\title{
Practice of Oncology in Low- income Setting: A Review of Four Years Activities in Togo
}

\author{
Ablavi A. Adani-Ifè \\ Department of Oncology, Sylvanus Olympio University Teaching Hospital of Lomé, Togo.
}

\begin{abstract}
Purpose: Until 2016, there was no oncologist in Togo. This study reviewed the first four years of activities in the practice of clinical oncology in the country to provide the cancer profile, the treatment, and outcomes of patients. Methods: We performed a retrospective descriptive study of patients diagnosed with cancer seen in oncology in Togo from March 2016 to March 2020. Data on presentation, staging, treatment, and outcomes were reviewed. Statistics were computed using SPSS. Results: A total of 897 patients were included. There were 625 women (69.7\%) and 272 men (30.3\%). The mean age at diagnosis was 53.48 years for men and 52.39 for women and more than half of patients were under 60 years. A cancer diagnosis was histologically confirmed in $81.2 \%$ of patients. For both sexes, breast cancer was the commonest followed by cervix cancer, colorectal cancer, prostate, and stomach cancer. In men, prostate cancer ranked first followed respectively by gastric cancer and colorectal cancer. The most common cancer in women was breast cancer followed by cervix cancer. Majority of patients $(60 \%)$ presented at a late stage. 531 patients $(59.2 \%)$ received at least one cancer therapy modality but more than half of treated patients did not complete their treatment. After fifty-eight months of follow-up, only 132 patients (14.7\%) in the all-study population are alive. Conclusion: This study describes the epidemiology and oncologic treatment in Togolese patients. Breast and Prostate are the leading cancer diagnoses in our population. Most patients presented at an advanced stage and the treatment was palliative in a majority of patients. There is an urgent need for early detection of cancer in Togo.
\end{abstract}

Keywords: Cancer- oncology- treatment- low-income setting- Togo

Asian Pac J Cancer Care, 6 (3), 289-296

\section{Introduction}

Cancer is now recognized as a major public health problem. In 2020, 19.3 million new cases were reported worldwide, with many of them occurring in low and middle-income countries. More than one million new cases were diagnosed in Africa [1].

The global burden of cancer is expected to increase significantly by 2030 ; in that year, an estimated 24.6 million new cases and 12.9million deaths will occur, and the vast majority of this burden will befall low and middle-income countries [2,3]. The increasing incidence in these countries is due to lifestyle changes, increased life expectancy, and the improvement of treating infectious diseases [4].

Togo is low- income country in west Africa located between Ghana in the West and Benin in
Submission Date: 04/21/2021 Acceptance Date: 06/28/2021

\footnotetext{
Corresponding Author:

Dr. Ablavi A. Adani-Ifè

Department of Oncology, Sylvanus Olympio University Teaching Hospital of Lomé, Togo.

Email: solangeadaniife@yahoo.fr
}

the East. According to the Global Cancer Observatory (GLOBOCAN) estimations [5], more than 5000 new cases were detected in the country in 2020. Cancer care was extremely limited until 2016 with no oncologist and only three pathologists based in the country.

In this study, we review the first four years of activities in the practice of clinical oncology in Togo. We aimed to describe the clinical and pathological characteristics of the patients seen at oncology, the treatment administered, the outcomes, and to discuss the difficulties encountered in the management of these patients in our poor resource setting. 


\section{Materials and Methods}

\section{Setting}

Togo is a low-income country in West Africa with an estimated population of 8.278 million (2020) [6]. Patients were referred from all over the country and from the neighboring countries, especially from Benin. From March 2016, patients were received in a private clinic and recently in the public hospital also as the oncology unit of the Sylvanus Olympio Teaching Hospital was established in January 2019. Only the adult cancer patients were managed, childhood cancer ( $0-14$ years) is treated in the pediatric oncology unit.

\section{Study population}

A total of 1065 patients were referred to oncology during the period under review (March 2016-March 2020) with an annual average of 266 patients. One hundred sixty-eight patients were excluded, 68 because of missing or incomplete information in the medical records; 100 because of presenting benign tumors. Data collected included demographics information (age, sex), tumor characteristics (histology and stage), treatment received, and outcomes.

\section{Diagnosis and staging}

All patients with histologically confirmed cancer and suspected cases of cancer on radiological findings and clinical presentations were included.

Computed Tomography (CT) scan was used for staging. The staging was assessed at the time of presentation and was determined according to the type of cancer by using the American Joint Committee on Cancer (AJCC) eight edition staging, the International Federation of Gynecology and Obstetrics classification, or Ann Arbor staging.

The stage was then classified as an early stage or late stage; cancer in stage I or II was considered as early stage and stage III or IV was defined as a late stage.

For the distribution of different anatomical sites of cancers, we used the international classification of diseases (ICD-10) adopted by the World Health Organization (WHO) in 2002.

\section{Cancer treatment and outcomes}

Data regarding specific cancer therapy were extracted. Patients were partitioned into three levels of treatment status

-completion of therapy

-Incompletion of therapy because of reasons other than abandonment of care

-abandonment of therapy.

Abandonment of therapy was defined as the inability to initiate medically indicated therapy.

The survival outcomes were classified as alive, deceased, or lost to follow up (for patients whose survival status could not be confirmed).

\section{Statistical analysis}

Statistical processing and analysis of data were performed using SPSS software.

Ethics approval

This study has been performed following the Declaration of Helsinki and has been approved by the "Comité de Bioéthique pour la Recherche en Santé (CBRS)" (Bioethics Committee for Health Research) from the Togo Ministry of Health, Ref N0: 0101/2016/ MS/CAB/DGS/DPLET/CBRS).

\section{Results}

\section{Characteristics of patients}

Eight hundred ninety-seven $(\mathrm{N}=897)$ patients were included in this study. The annual frequency of patients with malignancy tumors was 224.25 cases.

There were 625 women $(69.7 \%)$ and 272 men $(30.3 \%)$ with a sex ratio of 2.29 . The mean age of patients was $52.73 \pm 14.33$ years with an age range of 15 to 94 years. The mean age at diagnosis was 53.48 years for men and 52.39 years for women. More than half of the patients $(n=586,65.3 \%)$ were under the age of 60 years, one-fifth of them $(\mathrm{n}=176,19.6 \%)$ were below forty years old and thirteen percent $(n=117)$ were 70 years old and over. The highest number of cancer cases in men was seen in the 50-59 age group and for women, the highest number of cases was found in the 40-49 age group. The patient's characteristics are shown in Table 1. Breast cancer was the most common site of cancer seen at presentation $(\mathrm{n}=312,34.9 \%)$ following by gynecologic cancers $(n=177,19.3 \%)$ and digestive tract cancers $(n=157,17.5 \%)$.

\section{Diagnosis and staging}

Histopathology diagnosis of cancer was made in 728 patients $(81.2 \%)$. Pathology tissue was provided by either a surgical specimen or biopsy of the primary tumor or metastatic lesions.

The remaining patients had evidence of malignancy disease on imaging and or clinical presentation. Among these patients, 59 patients presented with a tumor in areas difficult to biopsy in our setting such as liver $(n=31)$, ovary $(n=15)$, pancreas $(n=11)$, and central nervous system $(n=2)$.

The most histologically confirmed cancer in our patients were breast cancer $(n=257,35.3 \%)$, cervix cancer $(n=70,10 \%)$, colorectal cancer $(n=41,5.6 \%)$, prostate cancer $(n=37,5 \%)$, stomach cancer $(n=37,5 \%)$ and uterine cancer $(n=34,4.7 \%)$.

Breast cancer following by cervix cancer, uterine cancer, ovarian cancer, and gastric cancer were the five most common cancer types in women. In men, prostate cancer was the most common cancer type following by gastric cancer, colorectal cancer, pharynx, and lung cancer.

Breast cancer was the most common cancer seen during the study period representing $35.3 \%$ of all the cancers. Seven out of the 257 breast cancer cases $(2.7 \%)$ occurred in men.

Table 2 shows the distribution of histologically confirmed cancer according to the site and sexe. 
Table 1. Characteristics of Patients $(\mathrm{N}=897)$

\begin{tabular}{llcc}
\hline Characteristics & & No of patients & $(\%)$ \\
\hline Sexe & & & \\
& Male & 272 & $(30.3)$ \\
Age & Female & 625 & $(69.7)$ \\
& & & \\
& $<20$ & 9 & $(1)$ \\
& $20-29$ & 40 & $(4.5)$ \\
& $30-39$ & 127 & $(14.2)$ \\
& $40-49$ & 191 & $(21.3)$ \\
& $50-59$ & 219 & $(24.4)$ \\
& $60-69$ & 194 & $(21.6)$ \\
& $70-79$ & 95 & $(10.6)$ \\
& $80-89$ & 20 & $(2.2)$ \\
& 90 and more & 2 & $(0.2)$ \\
& & & \\
Tiagnosis & Clinical only & 65 & $(7.2)$ \\
& Clinical and radiologic & 104 & $(11.6)$ \\
& Histopathology & 728 & $(81.2)$ \\
& & & \\
& Treatment & 531 & $(59.2)$ \\
& No treatment & 301 & $(33.6)$ \\
& Palliative care & 65 & $(7.2)$ \\
\hline
\end{tabular}

The most common histological subtypes were carcinoma $(n=616,84.6 \%)$, lymphoma $(n=43,5.9 \%)$ and sarcoma $(n=31,4.3 \%)$. Carcinomas were dominated by infiltrating ductal carcinoma $(n=243)$, adenocarcinoma $(n=181)$, and squamous cell carcinoma $(n=124)$; osteosarcoma and leiomyosarcoma were the most common histological type in sarcoma and large cell lymphoma was the most common histological type of lymphoma.

Of the 728 patients with histologically confirmed cancer, adequate staging assessment was available for 673 patients $(92.45 \%)$.

Overall, the majority of patients $(n=417,62 \%)$ presented with late-stage disease (stage III and IV) and about half of patients had stage IV disease $(n=334,49.63 \%)$.

\section{Treatment details and outcomes}

Of the 673 patients with histologically confirmed cancer and adequate staging, 513 patients $(76.23 \%)$ underwent some form of treatment for their cancer. Forty-eight patients $(7.13 \%)$ were referred for palliative care while 112 patients $(16.64 \%)$ did not receive treatment; these patients have abandoned care before the treatment could be initiated.

Half of the treated patients $(261 / 513,50.87 \%)$ underwent surgery. Of these, 196 patients $(75 \%)$ underwent an operation with curative intent while 65 patients $(25 \%)$ had a palliative operation.

Three-quarter of treated patients $(385 / 513,75.04 \%)$ received chemotherapy. Chemotherapy was done in 185 patients $(48 \%)$ in curative intent as neoadjuvant or adjuvant therapy and in 200 patients $(52 \%)$ as palliative therapy.
Sixty-seven patients $(67 / 513,13.06 \%)$ were treated by radiotherapy; radiation was palliative in 12 patients $(18 \%)$.

Hormonal therapy was done in 85 patients $(16.57 \%)$ who presented with hormone-sensitive cancer (breast and prostate cancers).

Among the 513 treated patients, eight patients (1.56\%) received target therapy. The target therapies used are trastuzumab (one patient/ breast cancer), Tarceva (one patient/lung cancer), imatinib (two patients/ GIST), sorafenib (two patients/hepatocellular carcinoma), and sunitinib (two patients/ renal cancer).

Among the 513 treated patients, 229 patients (44.64\%) completed prescribed therapy while 284 patients $(55.36 \%)$ did not complete their treatment. Breast cancer patients most commonly completed indicated treatment $(n=75 / 229)$.

The most common reasons for treatment incompletion were a progressive disease, cost, and availability of drugs or radiotherapy, fear of surgery, and timing of referral.

Of the 55 patients with histologically confirmed cancer without adequate staging assessment, four patients underwent surgery alone; the remainder did not receive any treatment.

Treatment details of patients with histologically confirmed cancer are shown in Table 3.

Among the 169 patients without a histological diagnosis, fourteen were treated. Of them, 11 patients received chemotherapy for choriocarcinoma and 3 patients received sorafenib for hepatocellular carcinoma diagnosed by radiology. Figure 1 summarizes the description of patients.

Overall, in all the study's population, 531 patients $(531 / 897,59.2 \%)$ received at least one specific therapeutic modality for their cancer, 65 patients $(65 / 897,7.2 \%)$ received palliative care and $301(33.6 \%)$ did not receive any treatment.

\section{Outcomes}

After fifty-eight months of follow-up, in the cohort of 531 treated patients, 227 patients $(42.7 \%)$ deceased, 127 (24\%) are alive, and 177 patients (33.3\%) had unknown outcome status as they were lost to follow up.

Overall, in the all-study population $(n=897)$, there were 336 patients $(37.5 \%)$ deceased and $132(14.7 \%)$ are alive. The remainder patients $(n=429,47.8 \%)$ were lost to follow up.

\section{Discussion}

This study presents the clinical, pathological, and therapeutic characteristics of patients received during the first four years of activities in medical oncology in Togo.

The annual frequency reported in our series (224 cases) is higher than that reported by Amégbor [7] in 2011 (210 cases) and Darré [8] in 2016 (217 cases) which suggests the increase in cancer cases in Togo.

The mean age in our study was $52.73 \pm 14.33$ years. This mean age is similar to that reported in Ghana [9] and Ivory Coast [10] but higher than those reported in Nigerian [11] and Ethiopian patients [12]. 


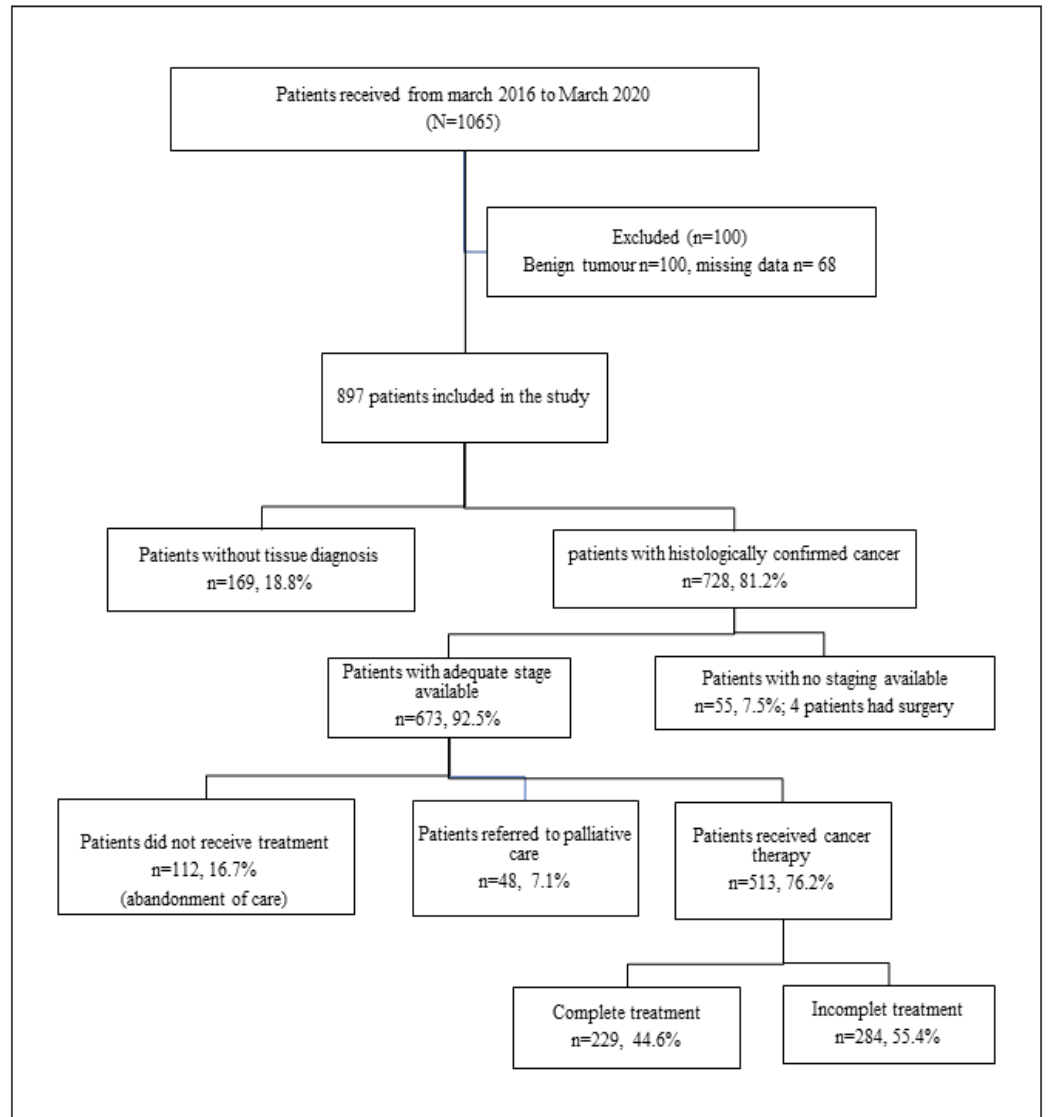

Figure 1. Description of Patients

In western countries, the risk of cancer increases with age and therefore, individuals aged 65 and over have the highest incidence rates [13]. Contrary to western countries, cancer seems to affect a younger population in our study. Indeed, more than half of our patients were under the age of 60 years.

In our study, the mean age of patients was slightly higher in men ( 53.48 years) than in women ( 52.39 years). The same results have been reported in several studies $[10,11,14,15]$.

The majority of patients in the study were female. This feminine predominance has already been reported in Togolese patients by Amégbor [7] and has also been observed in other studies in Africa $[9,12,15]$. This can be explained by the large proportion of breast and cervix cancer in our patients.

There are several stages in the care of patients with cancer including diagnosis, staging, treatment, follow up and palliation [16]. Pathological diagnosis of cancer is important for initiation of care but it remains difficult in our setting. Cancer's diagnosis in some sub-Saharan Africa countries is often solely based on a clinical diagnosis not verified through biopsy making cancer an even more difficult task [17]. Thus, it has been reported in the literature the high numbers of patient diagnosis clinically in Africa $[11,18,19]$.

In our study, a cancer diagnosis was based on clinical and/or radiology in one-fifth of the patients $(n=169,18.8 \%)$. Cancer of internal organs is difficult to perform a biopsy on because of the weakness of the surgery technical platform which doesn't allow some investigations to obtain tissue for pathological examination. In some cases, cancer subtype information is missing because of the cost of obtaining biopsies. In another way, some patients are reluctant to pursue with full diagnosis once the cancer is suspected due to cultural beliefs and the poor prognosis of the disease in our country.

Despite all these reasons, histological diagnosis of cancer was obtained in the large majority of the patients.

Our study showed that for both sexes combined and for all cancer sites, breast cancer was the commonest followed by cervix uteri cancer, colorectal cancer, stomach cancer, and prostate cancer.

This distribution is different from the 2020 GLOBOCAN estimation [5] which describes breast cancer following by prostate cancer, cervix cancer, colorectal cancer, and non-Hodgkin lymphoma as the top five of cancer in Togolese patients for both sexes.

Similar to other reports in the literature from sub-Saharan Africa $[9,19]$, the most common cancer type encountered in women were breast and cervix cancer. This high frequency of breast and cervical cancer is due to the lack of national cervical cancer or breast screening program in Togo.

In men, the most frequent cancer was prostate cancer following by stomach cancer, colorectal, pharynx, and lung cancer. Our findings are different from previous 
Table 2. Distribution of Cancers by Site and Sexe

\begin{tabular}{|c|c|c|c|c|c|c|c|}
\hline \multirow[t]{2}{*}{ ICD-10 } & \multirow[t]{2}{*}{ Site } & \multicolumn{2}{|c|}{ Male } & \multicolumn{2}{|c|}{ Female } & \multicolumn{2}{|c|}{ Both Sexe } \\
\hline & & $\mathrm{N}$ & $\%$ & $\mathrm{~N}$ & $\%$ & $\mathrm{~N}$ & $\%$ \\
\hline $\mathrm{C} 00$ & Lips & 1 & 0.4 & - & - & 1 & 0.2 \\
\hline $\mathrm{C} 01-\mathrm{C} 02$ & Tongue & 1 & 0.4 & 2 & 0.4 & 3 & 0.4 \\
\hline $\mathrm{C} 03-\mathrm{C} 06$ & Oral cavity & 7 & 3 & 6 & 1.2 & 13 & 1.8 \\
\hline $\mathrm{C} 07-\mathrm{C} 08$ & Salvary gland & 2 & 0.9 & 1 & 0.2 & 3 & 0.4 \\
\hline $\mathrm{C} 09-\mathrm{C} 14$ & Pharynx & 17 & 7.5 & 12 & 2.4 & 29 & 4 \\
\hline $\mathrm{C} 15$ & Esophagus & 7 & 3 & - & - & 7 & 1 \\
\hline $\mathrm{C} 16$ & Stomach & 25 & 11 & 12 & 2.4 & 37 & 5 \\
\hline $\mathrm{C} 17$ & Small intestine & 1 & 0.4 & 1 & 0.2 & 2 & 0.3 \\
\hline $\mathrm{C} 18-\mathrm{C} 21$ & Colon, rectum, anus & 22 & 10 & 19 & 3.8 & 41 & 5.6 \\
\hline $\mathrm{C} 22-\mathrm{C} 24$ & Liver, bilary tract & 4 & 1.7 & 3 & 0.6 & 7 & 1 \\
\hline $\mathrm{C} 25$ & Pancreas & 7 & 3 & 4 & 0.4 & 11 & 1.5 \\
\hline $\mathrm{C} 26$ & Other digestive cancers & 1 & 0.4 & 3 & 0.6 & 4 & 0.5 \\
\hline $\mathrm{C} 31$ & Sinuses & - & - & 1 & 0.2 & 1 & 0.2 \\
\hline $\mathrm{C} 32$ & Larynx & 5 & 2.2 & 1 & 0.2 & 6 & 0.8 \\
\hline $\mathrm{C} 34$ & Lung & 11 & 5 & 5 & 1 & 16 & 2.2 \\
\hline C37 & Thymus & - & - & 1 & 0.2 & 1 & 0.2 \\
\hline C38-C39 & Mediastin & - & - & 1 & 0.2 & 1 & 0.2 \\
\hline $\mathrm{C} 40-\mathrm{C} 41$ & Bone & 7 & 3 & 2 & 0.4 & 9 & 1.2 \\
\hline $\mathrm{C} 43$ & Melanoma of skin & - & - & 3 & 0.6 & 3 & 0.4 \\
\hline $\mathrm{C} 44$ & Other skin cancers & 9 & 4 & - & - & 9 & 1.2 \\
\hline $\mathrm{C} 49$ & Soft tissu & 8 & 3.5 & 11 & 2.2 & 19 & 2.6 \\
\hline $\mathrm{C} 50$ & Breast & 7 & 3 & 250 & 50 & 257 & 35.3 \\
\hline $\mathrm{C} 51$ & Vulva & - & - & 4 & 0.8 & 4 & 0.5 \\
\hline C52 & Vagina & - & - & 3 & 0.6 & 3 & 0.4 \\
\hline C53 & Cervix & - & - & 70 & 14 & 70 & 10 \\
\hline C54-C55 & Uterus & - & - & 34 & 6.8 & 34 & 4.7 \\
\hline C56 & Ovary & - & - & 23 & 4.6 & 23 & 3.1 \\
\hline $\mathrm{C} 57$ & Other & - & - & 1 & 0.2 & 1 & 0.2 \\
\hline C60 & Penis & 3 & 1.3 & - & - & 3 & 0.4 \\
\hline C61 & Prostate & 37 & 16.3 & - & - & 37 & 5 \\
\hline C62 & Testis & 2 & 0.9 & - & - & 2 & 0.3 \\
\hline C63 & Other & 1 & 0.4 & - & - & 1 & 0.2 \\
\hline C64 & Kidney & 5 & 2.2 & 2 & 0.4 & 7 & 1 \\
\hline C67 & Bladder & 7 & 3 & 3 & 0.6 & 10 & 1.4 \\
\hline C69 & Eye & 3 & 1.3 & 2 & 0.4 & 5 & 0.6 \\
\hline $\mathrm{C} 73$ & Thyroid & - & - & 5 & 1 & 5 & 0.6 \\
\hline C77-C80 & Metastasis & 2 & 0.9 & 3 & 0.6 & 5 & 0.6 \\
\hline C81 & Hodgkin disease & 6 & 2.6 & 2 & 0.4 & 8 & 1 \\
\hline C82-C85 & Non-Hodgkin Lymphoma & 10 & 4.4 & 5 & 1 & 15 & 2 \\
\hline C90 & Myeloma & 6 & 2.6 & 4 & 0,8 & 10 & 1.4 \\
\hline \multirow[t]{2}{*}{ C97 } & Double primary cancer & 4 & 1.7 & 1 & 0.2 & 5 & 0.6 \\
\hline & All Sites & 228 & 100 & 500 & 100 & 728 & 100 \\
\hline
\end{tabular}

reports from Togo where Prostate cancer was following by skin cancer and stomach cancer [7] or non-Hodgkin lymphoma and stomach cancer [8]. However, as previously reported stomach cancer remains the first digestive cancer in Togolese men.
Lung cancer is the most frequent cancer among males in developed countries [1]. Contrary to this result, the frequency of lung cancer was low in our study. According to GLOBOCAN 2020 [5], liver cancer is the fifth most common cancer in Togolese men, however, 
Table 3. Stage and Treatment Details in Patients with Histologically Confirmed Cancer $n=728$

\begin{tabular}{|c|c|c|}
\hline & No of patients & $(\%)$ \\
\hline \multicolumn{3}{|l|}{ Stage } \\
\hline No staging & 55 & $(7.5)$ \\
\hline Early stage & 256 & $(35.2)$ \\
\hline Late stage & 417 & $(57.3)$ \\
\hline \multicolumn{3}{|l|}{ Treatment } \\
\hline No treatment & 163 & $(22.4)$ \\
\hline Palliative care & 48 & (6.6) \\
\hline Cancer therapy & 517 & (71) \\
\hline \multicolumn{3}{|l|}{ Type of cancer therapy } \\
\hline Surgery & 265 & $(36.4)$ \\
\hline Chemotherapy & 385 & $(52.9)$ \\
\hline Hormonal therapy & 85 & $(11.7)$ \\
\hline Target therapy & 8 & $(1.1)$ \\
\hline
\end{tabular}

the frequency of liver cancer observed in our study is very low. This frequency can have been underestimated in this study because of the radiologic diagnosis of most cases of liver cancer.

Histologically, we noted a predominance of carcinoma as it has been reported in several studies [7,8,10,11].

The stage at diagnosis is a major determinant of survival from cancer.

In high-income countries, cancer staging usually consists of a combination of CT, Positron Emission Tomography (PET), and Magnetic Resonance Imaging (MRI) while most low-income and middle-income countries still rely on clinical examination, chest radiography, and ultrasound [20]. However, CT has become available in some major cities in sub-Saharan Africa [20]. CT and MRI are available in our country, therefore adequate staging was available for $92 \%$ of patients who had confirmed diagnosis of cancer. This rate is better than that report from Ghana [21], Malawi [14] and Pakistan [22].

The majority of the patients in this study $(62 \%)$ presented with a late-stage disease which is consistent with findings from other countries in Sub-Saharan Africa $[23,24]$. In our country, delay in presentation is often caused by cultural beliefs and misinformation, and patients are often seen first by traditional healers. In some cases, even when cancer patients have accessed the health care system, accurate diagnoses are difficult to obtain. Patients have to consult many health care professionals before final diagnosis and large numbers of health care professionals in Togo fail to recognize cancer in the patient and do not make the appropriate referral to an oncologist. So, cancer patients lose the precious time needed to treat and prevent the spread of their cancer.

Cancer treatment is the key determinant in the survival of patients but there are vast inequities in access to treatment between developing and developed countries [25].

In a study reported by Feuchtner and al at Addis-Ababa [24], one-fifth of the Ethiopian patients were not treated. In our study cohort, a third of the patients did not receive any treatment.

Surgical care is essential to cancer diagnosis, treatment, and palliation, however poor access to specialized oncology surgery remains a major obstacle to cancer in Low and Middle Incoming Countries [17, 26-28]. Inadequate surgical approaches can affect patient outcomes [20].

In our study half of treated patients underwent surgery, but most of the surgeries were performed by the general specialist who has not trained in surgical oncology. However, a majority of operated patients underwent surgery with curative intent. This result is in agreement with reports from Ghana where surgery was done in curative intend in $60 \%$ of patients [21], but different from reports from Malawi where the vast majority of surgical procedures were of palliative intent [14].

Cancer survival also depends on the use of chemotherapy, radiation, and/or hormonotherapy when appropriate.

In our practice, chemotherapy treatment is based on conventional cancer drugs. Most drugs in the WHO essential medicines list are available in select pharmacies but the main obstacle is the cost of these drugs. Indeed, many patients are covered neither by public health insurance nor by private insurance and have to pay out of pocket for their treatment.

Only 8 patients (\%) were able to receive target therapy, these drugs are too expensive and out-reach for most Togolese patients.

Radiotherapy plays an important role in oncology and can be used as the principal treatment variety of cancers [29]. It is also a highly effective treatment for palliation of cancer symptoms [30]. As in many other countries in Sub Sahara Africa [31], radiotherapy was not available in our country during the study period.

A major challenge to the treatment of cancer in Togo, as in the other low incoming countries is that most patients first present with advanced-stage disease. In these stages, treatment has a markedly diminished chance of success. Also, poor access to therapy negatively influenced the outcomes of patients. In this study, 531 patients $(59 \%)$ received at least one cancer therapy modality but less than half of them complete their treatment. This may explain the poor outcomes of our patients.

Follow-up allows for continued care, for the determination of recurrence and survival rates and is also used to detect late effects of treatment [16]. Unfortunately, many patients of our study population were lost to follow up.

This high rate of patients with unknown survival status and the retrospective nature of the study with data missing are some limitations of this study.

In conclusion, this study is the first to describe the basic epidemiology and oncologic treatment in Togolese patients. Breast and Prostate are the leading cancer diagnoses in our population. Most patients presented at an advanced stage. The gold of treatment was palliative in a majority of patients. There is an urgent need for early detection of cancer in Togo to make treatment more effective, less costly, more accessible, and acceptable to 
patients.

\section{Acknowledgments}

This study received no specific grant from any funding agency in the public, commercial or not-for-profit sectors.

The authors declare that they have no competing interests

\section{References}

1. Sung H, Ferlay J, Siegel RL, Laversanne M, Soerjomataram I, Jemal A, Bray F. Global Cancer Statistics 2020: GLOBOCAN Estimates of Incidence and Mortality Worldwide for 36 Cancers in 185 Countries. CA: A Cancer Journal for Clinicians. 202102 04;71(3):209-249. https:// doi.org/10.3322/caac. 21660

2. Boyle P, Levin B. World Cancer Report 2008. Lyon: International Agency for Research on Cancer, 2008.

3. International Agency for Research on Cancer (IARC): The Global cancer observatory (GLOBOCAN 2020). https:// gco.iarc.fr/ cancer tomorrow. Accessed 7 February 2021.

4. Farmer P, Frenk J, Knaul FM, Shulman LN, Alleyne G, Armstrong L, Atun R, Blayney D, Chen L, Feachem R, Gospodarowicz M, Gralow J, Gupta S, Langer A, Lob-Levyt J, Neal C, Mbewu A, Mired D, Piot P, Reddy KS, Sachs JD, Sarhan M, Seffrin JR. Expansion of cancer care and control in countries of low and middle income: a call to action. The Lancet. 2010 Oct;376(9747):1186-1193. https://doi. org/10.1016/s0140-6736(10)61152-x

5. International Agency for Research on Cancer (IARC): The Global cancer observatory (GLOBOCAN 2020). https://gco. iarc.fr/data/ facts sheet/populations/768-Togo-fact-sheets. pdf Accessed 7 February 2021.

6. www. Worldometers.info. Population of Togo. Elaboration of data by United Nations, Department of Economic and Social Affairs, Population Division. World Population Prospects: the 2019 revision.

7. Amégbor K, Darre T, Ayéna KD, Padaro E, Tengué K, Abalo A, Napo-Koura G. Cancers in Togo from 1984 to 2008: Epidemiological and Pathological Aspects of 5251 Cases. Journal of Cancer Epidemiology. 2011;2011:1-7. https://doi. org $/ 10.1155 / 2011 / 319872$

8. Darre T, Kpatcha TM, Bagny A, Maneh N, Gnandi-Piou F, Tchangai B, Dare S, Adani-Ifé S, Walla A, Amégbor K, Napo-Koura G. Descriptive Epidemiology of Cancers in Togo from 2009 to 2016. Asian Pacific Journal of Cancer Prevention. 2017 Dec;18(12). https://doi.org/10.22034/ APJCP.2017.18.12.3407

9. Calys-Tagoe BN, Yarney J, Kenu E, Owusu Amanhyia NAK, Enchill E, Obeng I. Profile of cancer patients' seen at Korle $\mathrm{Bu}$ teaching hospital in Ghana (A cancer registry review). BMC Research Notes. 2014;7(1):577. https://doi. org/10.1186/1756-0500-7-577

10. Effi AB, Koffi KE, Aman NA, Doukouré B, N'dah KJ, Koffi KD, Kouyaté M, Koui BBS, Hondé M, Diomandé MIJM. Descriptive epidemiology of cancers in Cote d'Ivoire. Bulletin du Cancer. 2013 02;100(2):119-125. https://doi. org/10.1684/bdc.2013.1695

11. Garba SM, Zaki HM, Arfaoui A, Hami H, Soulaymani A, Nouhou H, Quyou A. . Epidemiology of cancers in Niger, 1992 to 2009. Bulletin du Cancer. 2013 02;100(2):127-133. https://doi.org/10.1684/bdc.2013.1699

12. Rick T, Habtamu B, Tigeneh W, Abreha A, van Norden Y, Grover S, Assefa M, Incrocci L. Patterns of Care of Cancers and Radiotherapy in Ethiopia. Journal of Global Oncology. 2019 Dec;(5):1-8. https://doi.org/10.1200/jgo.19.00129

13. Belot A, Grosclaude P, Bossard N, Jougla E, Benhamou E, Delafosse P, Guizard A, Molinié F, Danzon A, Bara S, Bouvier A, Trétarre B, Binder-Foucard F, Colonna M, Daubisse L, Hédelin G, Launoy G, Le Stang N, Maynadié M, Monnereau A, Troussard X, Faivre J, Collignon A, Janoray I, Arveux P, Buemi A, Raverdy N, Schvartz C, Bovet M, Chérié-Challine L, Estève J, Remontet L, Velten M. Cancer incidence and mortality in France over the period 1980-2005. Revue d'Épidémiologie et de Santé Publique. 2008 06;56(3):159-175. https://doi.org/10.1016/j. respe.2008.03.117

14. Kendig. Cancer Treatment in Malawi: A Disease of Palliation. World Journal of Oncology. 2013; https://doi.org/10.4021/ wjon $683 \mathrm{w}$

15. Elidrissi Errahhali M, Elidrissi Errahhali M, Ouarzane M, Boulouiz R, Bellaoui M. Cancer incidence in eastern Morocco: cancer patterns and incidence trends, 2005-2012. BMC Cancer. 201708 29;17(1). https://doi.org/10.1186/ s12885-017-3597-6

16. Cazap E, Magrath I, Kingham TP, Elzawawy A. Structural Barriers to Diagnosis and Treatment of Cancer in Low- and Middle-Income Countries: The Urgent Need for Scaling Up. Journal of Clinical Oncology. 2016 01;34(1):14-19. https:// doi.org/10.1200/jco.2015.61.9189

17. Gyorki DE, Muyco A, Kushner AL, Brennan MF, Kingham TP. Cancer Surgery in Low-Income Countries. Archives of Surgery. 2012 Dec 01;147(12):1135. https://doi.org/10.1001/ archsurg.2012.1265

18. Msyamboza KP, Manda G, Tembo B, Thambo C, Chitete L, Mindiera C, Finch LK, Hamling K. Cancer survival in Malawi : a retrospective cohort study. Pan African Medical Journal. 2014;19. https://doi.org/10.11604/ pamj.2014.19.234.4675

19. Jedy-Agba E, Curado MP, Ogunbiyi O, Oga E, Fabowale T, Igbinoba F, Osubor G, Otu T, Kumai H, Koechlin A, Osinubi P, Dakum P, Blattner W, Adebamowo CA. Cancer incidence in Nigeria: A report from population-based cancer registries. Cancer Epidemiology. 2012 Oct;36(5):e271-e278. https:// doi.org/10.1016/j.canep.2012.04.007

20. Kingham TP, Alatise OI, Vanderpuye V, Casper C, Abantanga FA, Kamara TB, Olopade OI, Habeebu M, Abdulkareem FB, Denny L. Treatment of cancer in sub-Saharan Africa. The Lancet Oncology. 2013 04;14(4):e158-e167. https://doi. org/10.1016/s1470-2045(12)70472-2

21. Gyedu A, Gaskill CE, Agbedinu K, Salazar DR, Kingham TP. Surgical oncology at a major referral center in Ghana: Burden, staging, and outcomes. Journal of Surgical Oncology. 201808 10; https://doi.org/10.1002/jso.25168

22. Bhurgri Y, Bhurgri A, Pervez S, et al. Cancer profile of Hyderabad, Pakistan 1998-2002.Asian Pac J Cancer Prev. 2005;6(4):474-80.

23. Jedy-Agba E, McCormack V, Adebamowo C, dos-SantosSilva I. Stage at diagnosis of breast cancer in sub-Saharan Africa: a systematic review and meta-analysis. The Lancet Global Health. 2016 Dec;4(12):e923-e935. https://doi. org/10.1016/s2214-109x(16)30259-5

24. Feuchtner J, Mathewos A, Solomon A, Timotewos G, Aynalem A, Wondemagegnehu T, Gebremedhin A, Adugna F, Griesel M, Wienke A, Addissie A, Jemal A, Kantelhardt EJ. Addis Ababa population-based pattern of cancer therapy, Ethiopia. Bowles E. PLOS ONE. 2019 09 19;14(9):e0219519. https://doi.org/10.1371/journal. pone. 0219519 
25. de Souza JA, Hunt B, Asirwa FC, Adebamowo C, Lopes G. Global Health Equity: Cancer Care Outcome Disparities in High-, Middle-, and Low-Income Countries. Journal of Clinical Oncology. 2016 01;34(1):6-13. https://doi. org $/ 10.1200 /$ jco.2015.62.2860

26. Price AJ, Ndom P, Atenguena E, Mambou Nouemssi JP, Ryder RW. Cancer care challenges in developing countries. Cancer. 2011 Dec 16;118(14):3627-3635. https://doi. org/10.1002/cncr.26681

27. Hoekstra HJ, Wobbes T, Heineman E, Haryono S, Aryandono T, Balch CM. Fighting Global Disparities in Cancer Care: A Surgical Oncology View. Annals of Surgical Oncology. 201604 01;23(7):2131-2136. https://doi.org/10.1245/ s10434-016-5194-3

28. Zogg CK. Recognition of surgical need as part of cancer control in Africa. The Lancet Oncology. 2013 07;14(8):e289. https://doi.org/10.1016/s1470-2045(13)70210-9

29. Price P, Sikora K. Treatment of Cancer (ed 5). London, United Kingdom, Arnold Hodder, 2008.

30. Barton MB, Frommer M, Shafiq J. Role of radiotherapy in cancer control in low-income and middle-income countries. The Lancet Oncology. 2006 07;7(7):584-595. https://doi. org/10.1016/s1470-2045(06)70759-8

31. Abdel-Wahab M, Bourque J, Pynda Y, Iżewska J, Van der Merwe D, Zubizarreta E, Rosenblatt E. Status of radiotherapy resources in Africa: an International Atomic Energy Agency analysis. The Lancet Oncology. 2013 04;14(4):e168-e175. https://doi.org/10.1016/s1470-2045(12)70532-6

\section{(c) (i) (8)}

This work is licensed under a Creative Commons AttributionNon Commercial 4.0 International License. 